\title{
The Determinants of Motivation Regarding Top Competitive Basketball of Juniors
}

\author{
Katarína Šimková, Hana Válková \\ Faculty of Sports Studies, Masaryk University, Brno
}

\begin{abstract}
The motivation plays an essential role in carrying out any activity in people's lives. It is a critical aspect between individual stages of career transitions and its goals. The purpose is to describe the determinants of the motivation and adherence of junior basketball players. The research interviews 40 players who wish to continue at the professional stage. The Career Transition theory (Alfermann \& Stambulova, 2007) is a scope for the research. The research is qualitative, using The Grounded Theory by Strauss and Corbin (1990). The chosen research instrument was a semi-structured interview. The sample consists of twenty girls and twenty boys between ages 15-18. The results illustrate eight determinants of motivation and adherence. 1. lifestyle, 2. the perception of competencies, 3. specifics of basketball, 4. biopsychosocial health. 5. enjoyment, 6. team spirit, 7. society, 8. time management. Time management is the most occurring reason for termination of the basketball career.
\end{abstract}

Keywords: motivation; transition; time management; determinants of motivation; basketball, juniors, skills; career transition; lifestyle; adherence; passion; health; team spirit, coach.

\section{INTRODUCTION}

The concept of motivation falls within the sphere of psychology terminology. It interferes with the life of a person in every aspect of life. The determinants of motivation are present in several areas. Those represent individual characteristics and personal potential. Social and biological factors determine psychological factors. These three areas cannot exist in isolation. The development of human psyche depends on biological factors within the nervous system. Social determinants refer to a person as part of society. It develops, influences, and shapes the person with specific social standards, culture, and civilization (Čechová \& Rozsypalová, 1992). Since psychology is a discipline with many theoretical frameworks, many of the theories mentioned are of the older date. It is my preference to work with original works that the new theories built upon.

Motivation has been repeatedly reported as one of the most important contributors to highlevel performance. For instance, in sport, athletes' success is often explained as a function of motivation (Gould et al. 2002).

Sport is a specific environment with precise requirements for its participants. If the motivation of participants is low, there is a weak incentive for hard work. They may get further from reaching a professional level in one's career. Motivation is the foundation of sports performance and success. It relates to experiences the athlete undergoes. Sportsperson then responds to the sport in their individual way (Duda \& Treasure, 2010). We can distinguish three basic types - amotivation, internal and external motivation. 1. External motivation builds on external rewards. Trophies, prizes, praise, status, and a pay check. 2. Internal motivation comes from the inside of a person: enjoyment, fun, enthusiasm for action, demonstration or improvement of abilities. Amotivation means a lack of internal and external motivation for sporting activities (Jarvis, 2006).

The need for achievement is a theory focusing on actual sporting activity. Need for achievement describes the process of mastering the top competitive sport. It includes high sporting performances and diverse activities of life. This embodies the creative self-image of an athlete's 
personality. To construct the consistency of the general and specific objectives of society and the individual is imperative. Need for achievement has resources in the long-term learning process and various motives prevailing at different levels. Top sporting performance is the result of the complexity of motives that energize, maintain, create and strengthen the stages of motivation. It is the foundation of the activity and the result of sporting performance (Vaňek, Hošek \& Man, 1989).

Self-determination theory (Ryan \& Deci, 2002) was initially developed by Edward L. Deci and Richard M. Ryan and has been elaborated and refined by scholars from many countries. Sport is a specific environment with specific requirements for the participants. Without motivation, the pillars for continuation on an elite level are weak. Motivation represents the fundamentals for sports performance and success. (Duda \& Treasure, 2010). Sports psychologist Gurský (2005) describes motivation as a process of managing, maintaining and energising behaviour. Motivation can be seen in more ways than one. Self-determination theory (Ryan \& Deci, 2002) propositions focus on how social and cultural factors facilitate or undermine people's sense of volition and initiative, in addition to their well-being and the quality of their performance. The theory makes distinctions between different types of motivation and the consequences of them. 1. Intrinsic motivation is the natural, inherent drive to seek out challenges and new possibilities associated with cognitive and social development. 2. Extrinsic motivation comes from external sources. The different forms of extrinsic motivation and the contexts in which they come about, these contexts affect whether the motivations are internalised and so integrated into the sense of self. Four different types of extrinsic motivations often vary in terms of their relative autonomy:

Externally regulated behaviour: Is the least autonomous, it is performed because of external demand or possible reward. Such actions can be seen to have an externally perceived locus of causality.

1. Introjected regulation of behaviour: describes taking on regulations to behaviour but not fully accepting said regulations as your own. Deci and Ryan claim such behaviour normally represents regulation by contingent self-esteem, citing ego involvement as a classic form of introjections. This is the kind of behaviour where people feel motivated to demonstrate the ability to maintain self-worth. While this is internally driven, introjected behaviour has an external perceived locus of causality or not coming from one's self. Since the causality of the behaviour is perceived as external, the behaviour is considered non-self-determined.

2. Regulation through identification: a more autonomously driven form of extrinsic motivation. It involves consciously valuing a goal or regulation, so that said action is accepted as personally important.

3. Integrated Regulation: Is the most autonomous kind of extrinsic motivation. They are occurring when regulations are fully assimilated with self, so they are included in a person's self-evaluations and beliefs on personal needs. Because of this, integrated motivations share qualities with intrinsic motivation but are still classified as extrinsic because the goals that are trying to be achieved are for reasons extrinsic to the self, rather than the inherent enjoyment or interest in the task.

The third type is called amotivation - internal or external motivation is missing (Jarvis, 2006). Another view regards differences in quantity and quality of motivation. Quantity - frequency of engagement in sport "here and now", achieved success. Quality refers to the positive enjoyment with the sport (Duda \& Treasure, 2010). The actual sporting activity creates both the short-term and the long-term process of exceptional performance - achievement motivation (Vaňek \& Hošek, 1989).

In Study with French junior national tennis players and fencers, results revealed the presence of different levels of autonomous and controlled motivations. Results show that athletes with the least self-determined motivational profile obtained lower levels of subsequent tennis performance than those with more self-determined motivation. The least self-determined motivational profile led to the lowest level of performance. They used cluster analysis, which siggests that this way 
of analysis is useful in the understanding of the complex relationship between motivation and performance in elite sport (Gillet, et al. 2009).

Achievement goal theory (Nicholls, 1984; Duda, 1992) falls under the concept of the need for achievement. The theory distinguishes two types of motivation depending on the orientation of sportsperson. 1. Task orientation and 2. Ego orientation. The orientation influences the structure of the goal in sports. The process creates a specific motivational climate. We distinguish two dimensions. The mastery and the performance; both based on the orientations either on the task or the ego (Ames, 1992). The motivational climate is a result of the coach's educational approach and the experience gained through the implementation of the activity.

The mastery (task-orientation) refers to a structure of climate that encourages effort, cooperation, has emphasis on learning and mastering the task. The task-oriented motivational climate shaped by the coach helps to increase internal motivation and adherence to the sport. Coach uses the training environment as a place of education and knowledge about more than the sports (Almagro et al., 2009). Task-oriented athletes usually have a higher motivation than ego-oriented athletes. It is essential to consider a personal improvement, individual mastery, and improvement since the last performance. Success is assessed by self-performance and personal development (Lochbaum \& Roberts, 1993). Greater autonomy is another factor considered a solid motive. More mature individuals can make decisions according to their will. They should be free to choose if they wish to continue further. If the adolescents get to decide the use of their time, their motivation may increase (Dawes et al., 2013). Performance (ego-orientation) refers to situations that lead to normative comparisons and higher competition between teammates. Teachers and coaches usually penalize participants for their mistakes (Ames, 1992). The coach emphasizes processing of the information in a normative manner. Comparison with the chosen standard, which reduces the athlete's sense of control over their activities and the consequent results in sport (Duda \& Hall, 2001). Ego-oriented individuals value the demonstration of their abilities (Vallerand \& Losier, 1999). They evaluate their success or failure by comparing their performance with that of the others (Lochbaum \& Roberts, 1993). The task-oriented youth is motivated more internally. They experience a lot of enjoyment and successes than ego-oriented individuals (Gómez-López, 2013). Positive experiences in sports are a great predictor of further sports engagement. They help to expand the motivation to continue. Dworkin et al. (2003) describe six key areas of experience: 1. exploration and identity; 2. initiative; 3. self-regulation; 4. peer relations; 5 . teamwork and social skills, 6 . social networks with adults. The specific model of the motivational structure defines the level of all the stages in the motivational structure, the level of one's sporting performance, the level of the competition in which the athlete has the opportunity to realize their self. 1. Biological motivation: status, needs, expressions of the athlete's organism. 2. Material motivation: the relationship between life and sport, prizes, rewards, the study of sport, a profession in sport, the realization of self in the sport. 3. Educational motivation: development of learning, the influence of a coach, self-educating, self-improvement, sports performance, goals in sport and life. 4. Psychological motivation: a manifestation of personality, abilities, and skills, characteristics, will, overcoming psychological burdens, hardiness and resilience 5 . Social motivation: competition in sport, relationships with teammates, social learning, role models, handling the social status of the top athlete, the influence of the specific and global environment of sport and society. 6. Political motivation: peace as a product of sport and policy of peace, gaining knowledge about people, establishing opinions, getting to know the world, engagement and all-round growth of the athlete's personality (Macák \& Hošek, 1989). 


\section{Passion and adherence}

Motivation overlaps with passion. It is a catalyst, an energy supplier that is persistent and strategic in high-demanding activities. The passion has two dimensions - harmonious and obsessive (Vallerand et al., 2003). Harmonious passion is a predictor of mastery goals, based on autonomous internalization. Individuals are not compelled to do the activity; they freely choose to do so. Other areas of life coexist with performing the selected pursuit. Elite performance is achieved through the obsessive passion of athletes who concentrate exclusively on their sport at the cost of other areas of life. It is the result of controlled internalization. The inner impulse forces a person to execute the activity even at inappropriate moments (Vallerand et al., 2008). Adherence means 'loyalty' to the given program of chosen activity. It is found in activities that are the result of free choice. Another aspects are the efficacy of a program and social support, interpersonal relationships, whether positive or negative (Slepička \& Hošek \& Hátlová, 2009).

\section{Career Transition theory}

The Career Transition Theory (Alfermann \& Stambulova, 2007) focuses on the different stages of a professional sports career. A transition is an event that results in a change in thinking about oneself and the world in which the individual lives. It requires an adequate behavioural change. Athletes must meet the specific requirements of adjustment (practice, competition, communication, lifestyle). Several authors describe specific stages with similar content: 1. Preparatory stage; development of movement and motor skills filled with a wide range of sports activities to which the child dedicates its time. The critical aspect is to present and develop a good atmosphere, especially during periods when parents play a significant role as a principal socializing agent. 2. Start of sports specialization or initiation stage (Salmela 1994, Bloom 1985). Sport is rather a game, the individual may try many activities to clarify which one is best for them. 3. Intensive training in selected sports or specialization years (Cote, 1999) / development stage. The focus is on 2 to 3 sports; individuals devote their time to them. Activities require specific knowledge of the chosen sport, they develop skills and abilities and create an emotional relationship with the given activity. 4. Cultivation stage or stage of perfection/investment years; the athlete becomes an expert in selected sport, reaches an elite level, or a senior level in the sports profession. They achieve their highest performances. 5. Final stage or maintenance years is preparation for career termination. Sporting performances still hold a certain level, but there are no significant records. Athletes have enough strength to sustain a professional sports career. Their engagement is gradually decreasing. Some authors describe the stage as an interruption of sports career (Wylleman $\&$ Lavallee, 2004) or recreational years. Athletes cease to participate in a high a level of sport but may continue recreationally.

Junior athletes are at the developmental stage (specialization years or intensive training in selected sport). Athletes narrow their attention and engagement to one or two sporting disciplines that interest them (Alfermann \& Stambulova, 2007). Sports engagement means the extent to which young people perceive activities as entertaining, exciting and challenging (Vallerand $\&$ Losier, 1999). Sports engagement and sports career of an adolescent is distinguished by intensity - the frequency with which they participate in a chosen activity; and length - how many years they have participated in chosen activity (Bohnert et al. 2010).

The model of four stages of the motivational structure by Vaněk and Hošek (the first one to mention three main phases is Stránsky) describes the primary motives of different age categories. 1. Stage of the first expansion of movement (biological motives, need for movement, positive excitement, parents as role models, and other athletes). The participants are around ten years old; performed activities are diverse, performance is based on entertainment and playing. The critical role of the coach is to create a positive attitude towards sports, to teach the basic principles of movement and skills. There is a possibility of an early specialization of the individual. 2. Stage of 
selective self-realization - youth and adolescents (motives are a social claim, performance, success in conjunction with a positive experience). The incentive is a gradual sports specialization, specific training, and moderately high performance. The key role of the coach is 'to have good luck with the personality type the coach will be.' He should be able to push the player forward, give him the knowledge and values about sport and life itself. 3. Stage of sports mastery - adulthood (the motivational structure is differentiated, importance is on personal success, social prestige, economic status). Specialization in a specific sport is high. The key role of the coach is to create cohesiveness in the team and to maintain high performance. 4. Involution of the motivational structure (the involution of elite performance, socio-psychological problems for leaving the 'glory' stage, changes in economic status). It involves a period of higher maturity, specialization in a chosen sport, keeping advanced performance. The role of the coach is to maintain the team harmony. He should represent an adequate example for children and youth. Each stage is full of internal and external influences that are interconnected. Together they shape the athlete's personality, their system of values, characteristics and structure of sports motivation (Votík, 2011). Career Transition theory and the model of motivational structure is the framework of this research.

\section{Transitions}

Transitions between stages can be predictable (normative) organizationally or structurally. They may be associated with changes in sports achievements or with changes in age (initiation of the competitive sport, transition from high school to college). Unpredictable transitions (non-normative) occur unexpectedly or do not occur at all. They are also called non-events which points to changes when the transition is expected but does not ensure for specific reasons (Petitpas et al., 1997). The motivation for the transition can be socialization and the influence of important people (family and peers); behaviour related to the transition period (work ethics, maximizing options of sports selection, focus on transition); internal motivation (love for the sport, love for a particular activity, voluntary sports sacrifices). Perception of the transition may raise uncertainty of new experiences (perception of increased standards, lack of control); emotional reactions associated with the transition (stress levels, negative experiences, positive transition experiences). Sources of stress associated with transition are external and internal pressures; lack of support from the institution, organizational pressures, lack of school support; the pressure of sports careers and lifestyle (conflicts between the sport and education. Support for sports development associated with sport is support from a coach, informational support; material support, emotional support and support of self-confidence; institutional support - school support for sports participation, organizational support. Changes associated with ending of the transition may be: changes associated with sport - increased technical skills and knowledge, increased importance of sport; psychological development - identity-related changes, psychological changes - coping, self-confidence, nervousness; changes associated with socialization - benefits of transition (friendships); negative impacts (lack of time for friends), loss of contact (Pummell, Harwood \& Lavallee, 2008).

Dual career, defined as a career with the major foci on sport and studies or work (Stambulova \& Wylleman, 2014), also consists of dual career transitions which are athletes' simultaneous transitions in sport and education or work.

The transition from junior to senior plays the most critical role in the overall sports career. Athletes themselves often describe this stage transition as the most difficult. Many sportspeople have admitted they have failed to cope with the demands. Some athletes do not manage the transition. They stagnate, stay with the sport recreationally or terminate sporting activities completely. They may feel tense, observe lack of progress, or have alternative goals. Other complications could be interpersonal conflicts with the coach and training environment, lack of leadership and personnel management in sports (Hollings et al., 2014). 


\section{Characteristics of the adolescence and the stage of selective self-realization}

Adolescence is a crucial period for young athletes to become regular participants of physical activity, or to omit it altogether. Youth participation in sport accounts for the highest percentage of time dedicated to the activity if it is structured and voluntary (Czikszentmihalyi \& Larson, 1984; Larson \& Verma, 1999). The motivation during training and competitions is a determinant for youth's sports engagement (Almagro et al., 2009).

One of the most critical factors is the culture and environment in which an individual grows, studies and develops their professional focus. Few studies explore cultural factors that may have an emphasis on development of the specific motivational goals among youth. Their perception may be different from the cultural perspective (Ryska, 2001). Maehr and Nicholls (1980) have pointed out the importance of the perceived cultural context and its impact on the type of motivational orientation of the individual growing in it. Physical culture reflects cultural values, needs, activities, norms, and relationships. There is a connection with material and spiritual culture, thus modelling concepts such as physical exercise, mass recreation, or sport. The basic function of physical culture is the satisfaction and cultivation of the natural need for motion, the renewal of physical and mental forces (Charvát, 2002).

\section{Purpose}

There is a need to comprehend how youth basketball players perceive their career and participation in sporting activities. The benefit is to understand why basketball youth choose basketball as a professional career, which facets of sports they might maintain in recreational sports. The research strategy is qualitative, focused on the environment of the Slovak Republic with its specifics. The research aims to formulate determinants of motivation that relate to the stage of selective selfrealization of junior basketball players, leading them to continue playing professional basketball. Research question

(1). Which determinants relate to the motivation of basketball juniors players?

(2). Are there gender differences relating to the determinants of the motivation?

\section{METHODS}

\section{Research design}

Qualitative research can capture the multidimensionality of meanings, contexts, unexpected phenomena, processes and explanations found in the world of sport, games and physical activity (Stelter, Sparkes and Hunger, 2003). The number of such research designs has increased in recent years. Sports psychology has a room for further qualitative studies (Munroe-Chandler, 2005).

Grounded theory is a research methodology which operates inductively. A study using grounded theory is likely to begin with the collection of qualitative data. Researchers review the collected data with one goal in mind. They look for repeated ideas, concepts or elements which become apparent. These are tagged with codes, extracted from the data. As more data is collected, and re-reviewed, codes can be grouped into concepts, and then into categories.

The analysis according to the Grounded Theory is carried out in three main steps (open coding, axial coding, selective coding). Opening coding identifies anchors that allow the key points of the data to be gathered. Everything is conceptualized line by line. Axial coding collects codes of similar content into the groups, which are later grouped in broader, similar concepts to create categories. Axial coding uses paradigm consistent of phenomena, direct causes, intervening causes, actions/interactions, consequences, and context. Selective coding is done after having found the core variable. The core explains the behaviour of the participants in resolving their main concern. After the core variable is chosen, researchers selectively code data with the core guiding their coding, not bothering about concepts with little importance to the core and its subcores. 


\section{Research instrument}

The data were collected via semi-structured interview. Questions were divided into three main parts regarding time - past and first experiences with sport and basketball, transition to the current junior stage and its difficulties; the presence and the dreams of the future. These three parts then focused on physical, social and psychological aspects of playing sports which were asked only if the participants had problems to talk about their experiences. The collection, analysis and interpretation process was conducted according to Strauss and Corbin's approach to Grounded theory (1999). The analysis was done using the software Atlas.ti, a program for the transparent processing of results, codes, subcategories, categories, and final paradigms.

The number of interviews differed from person to person - some recordings were about 30 minutes long, some took a bit over an hour. According to this, the transcribed pages ranged from 5 to 20 pages long.

\section{Participants}

The research group consists of 40 junior basketball players with an age range of 15-18. The choice of participants intended to have a uniform gender distribution of twenty boys and twenty girls. The main criteria are the age (15-18), the interest in continuing the basketball career professionally. The sample of players is from every part of Slovakia where the participation is the highest.

The interviews were obtained with players residing in five cities. Boys are from Bratislava, Prievidza, Žilina, Nitra, Košice, Poprad, Komárno / Trnava. Girls are from Banská Bystrica, Prievidza, Nitra, Košice, Ružomberok, Stará Turá / Pieštany.

\section{The course of research and analysis}

Each participant signed the informed consent; educating them about the research and its purpose with contact information. They had the right to withdraw from the interview or to keep silent about specific questions. Every interviewee agreed to recording on the audio. All audio recordings have transcriptions. Names and identifying markers were omitted to keep the anonymity.

Triangulation was provided through feedback of the coaches from the areas and places where the respondent's practice. Feedback was positive. The coaches discussed the importance of the determinants which appear in the results.

\section{Limits and positives}

Limitations were difficulties in time management, geographical extent and gathering the right amount of sufficient respondents to meet the criteria. One of the limitations is also the age and need for informed consent given by their parents or legal guardians who might refuse.

An intimate atmosphere regarding safety and space for an in-depth interview is one of the positives. This type of research gives the opportunity for young people to express themselves freely. They are allowed to speak about any topics that may be unknown by coaches, parents or friends about the motivation phenomena.

\section{RESULTS}

Basketball players in this age category have a solid idea of whether to continue their basketball career professionally, recreationally or leave the sport altogether. The paradigmatic model of the grounded theory demonstrates the complexity of youth motivation:

Phenomena: basketball and sport as a lifestyle; perceived own competencies; the game itself (collective sport, dynamics - action, technique, connecting with the ball, basket throws); balance 
(study - dual career). These are the main determinants of motivation, which plays an active role during the stage of selective self-realization.

Direct causes: coach; training process; support. These determinants are in close association with the phenomena described above. They determine the choice of a future career in sport, especially if the cohesiveness between the phenomenon and the causal conditions is disturbed.

Intervening causes (remote impacts): people outside the sporting environment; winning; physiology; first experiences with sports.

Context: environment and conditions, enthusiasm (love and joy of sport). These determinants exist somewhere between the thin lines of basketball as a sports discipline, coach and team, and perspective of the future.

Actions / Interaction: first experiences (strong memories); career self-reflection; sacrifices for sport; the benefits of sport.

Consequences: Future Prospects (Professional Sport + Study Selection + Recreational Engagement).

The apparent eight areas of determinants of motivation answer the first research question: 1. Which determinants relate to the motivation of basketball juniors players?

\section{Lifestyle}

Sport and basketball represent a lifestyle, a part of the player's identity. "Especially because of that sport, when I am doing it my whole life or at least most of my life, I can see it in myself, in my health, it is reflected in my life." They spend their spare time playing basketball, as a hobby and as a habit. "It's a daily thing, as I go to school every day, I am going to train every day." They cannot imagine life without a sport or training. Otherwise, they become bored and begin searching for another physical activity. It embodies an active engagement and passive engagement (as a fan, researching information via the media and internet). "My dad took me to see men's league, and I fell in love with basketball, I created a close relationship with it."

Everything is affected by their first experiences with the sport. Positive experiences are about seeing the worth in basketball. Negative ones are overcoming obstacles and proving themselves. "As a little boy I larked with my friends, leaped over the trees, climbed the constructions, so I was used to the intensity, I played with my brother, and with his help, I performed better." The perceived benefits of sports influence the lifestyle led at a younger age. They are called mental skills. Taking responsibility for themselves and others, developing their abilities, feeling their leisure time is profitable for themselves both mentally and physically, avoiding unhealthy habits and activities.

\section{Perception of one's competencies}

Adolescence is a time when youth realizes their abilities through organized sporting activities and learned basketball skills. Goals and goal setting lead them to constant improvement. They resist stagnation and are in constant pursuit of new goals even beyond their performance. "I know my goal, I know what I want to achieve, and I am going after that."

Improvement accompanies a sense of success, refining basketball skills - physical, mental and social. "Day to day, you suffer at the training, sweat the soul out, you come here to fight. You know you are ready for it, you see your everyday process and progress, you move on from match to match which motivates you to continue. This is what I learned, and I can learn something new when I go further."

High performance means more than winning. The perception of their potential shows them how far they can proceed when working hard. They aspire to ensure their basketball or sports career; they want to improve with a focus on the term - I WANT. "I want to make my money, play 
professionally, I want to play abroad, I want to feel it - WANT. I want to belong at the top. I want to play in (foreign country) because they are the second best in the world right after America and I think I can do it."

Coach contributes to the perception of their competences, as long as players get enough freedom to prove themselves on the court - both as a team and as an individual. Every player who works hard to get on the court should be treated fairly according to their skills. The coach should teach new things, not only about basketball but life as well. They need to be specific about what is done wrong and how to do it better, how to overcome obstacles. Unwavering position in the team confirms their competence. Players motivate each other to move forward. Another important aspect is support - material support from parents, informational support from the coach, emotional support from family, coach, team, friends. "Certainly, my parents motivated me to go to training because we do not live in the (city). They drive me twice every day. My parents are also entangled in it." "Probably my mom. She goes to my matches. She supports me; she encourages me."

None of this is possible without the respect and honor towards the people around them, against the opponents and their game, which improves the player himself and increases their competencies. "At the moment, probably the most that I have the chance to get to represent my country, Slovakia."

\section{Basketball specifics}

Basketball as a collective sport is a major reason why young people begin with practice. The collectivism is also a reason why they stayed with it for such a long time and wish to continue. "In time I found out that I enjoy it as a team. When we won together, we had to pull our weight as a team, it's about a shared experience."

As a team sport, it helps to establish strong relationships inside and outside of the court. The need to cooperate with others teaches tolerance and respect. Getting along with different personalities can lead to a further increase of social competencies. Dynamics and action of basketball (speed of the game, thought processes, tactics, quick decisions, reading teammates and opponents). "There is always something happening, observing the attack and defence at once. Other sports don't have that. There is always something interesting to see; something is still going on." "It's more gripping; you have to think, to have that players logic or something like that."

The considerable importance is connecting with the ball. The touch of a ball recalls the passion for basketball. The basketball is an extension of the body; it becomes the one with the player. It may associate with past experiences of the moment they touched the ball for the first time. This often helps to manage sports crisis. "I enjoyed it since childhood, to throw a basket, it's made for me. I was in preschool, threw a basket even when I had no idea what a ball is."

The training process plays a role in understanding the team as a whole and understanding individual members. Coach has to be a part of the team as a partner. He should be willing to try new things, be forward thinking, use the help of media, design suitable training sessions for their players based on their needs collectively and individually. Basketball builds the player physically, which includes the importance of strength and endurance, accuracy, balancing their life and plays part creatively. "Physical condition, we are keeping healthy, we are sportspeople, and we are fit. We have better health than people who sit on a couch at home, for sure."

Last but not least, the passive participation and patterns mentioned are watching basketball on $\mathrm{TV}$, reading books, searching for inspiration in the world. "They motivated me, the big payers of the NBA." 


\section{Time management}

This determinant is often the biggest reason for terminating the basketball career. It is important when balancing school with sports and personal life with sport.

Balancing the school and sport means to find time for both parts. The importance lays on the tolerance of teachers and coaches. Their cooperation should create conditions for players to meet the requirements of both sides. "I am starting college soon, and it would be nice to earn money by doing something I love. However, I know it's hard to do that, one injury and you are done."

Balancing personal life and sport focuses on enough time for friends and family, often on the sidelines. Their families display understanding providing huge support. This determinant may influence setting up player's future potential family. 'I am not sure how to say this. Yes, I would go for it if I had time for everything I want to do.'

\section{Health - the biopsychosocial point of view}

From a biological point of view, the sport is significant for health (good physical condition, stamina, endurance, keeping high performance at an older age). "I won't be sitting at home; I do something for my body. Then I feel better about myself."

From the social point of view, sport provides specific socialization. The athletes belong to a certain group of people with whom they have at least one thing in common. "That is what's so amazing about the sport, about the collective. Even if someone turns their back on you, teammates will be there for you."

They learn communication and interaction through problem-solving, verbal and nonverbal communication, openness and honesty. Those are factors without which the team cannot function as a cohesive unit. "He taught us when there's a problem we should say it right away so it won't suffocate us. They taught us to communicate."

From the psychological point of view, it helps to relax and to gain the psychological well-being. By training and playing, they exhaust themselves physically but energize mentally. "... that I can relax on the court. Not physically, but mentally. When I go there, I throw away all the bad thoughts or things that happened through the day."

Basketball is often described as entering another dimension of life. Young players go through self-development when gaining knowledge about different cultures, different environment, and personalities. "We visit many cities; we have many experiences as a team. We get to know new people, that sport gives me a lot for my life. I am growing up with it."

Basketball can provide a sense of life. A fulfilling activity with many future possible achievements when setting direct and indirect goals. "I like when the match shows it has a sense, that we move forward."

\section{Enjoyment}

Enjoyment combines all the determinants mentioned so far. It is imperative to keep enthusiasm in the various transitions through different career periods. Many individuals are afraid of moving to a professional level to not to lose the passion. Thus, it is vital for the other determinants to be present to maintain the zeal of basketball and sport as such. "It fulfills me, that is what pulls me to it, I enjoy it so much. For me, basketball is a sport that I relish in."

\section{Environment}

The conditions and options of clubs and countries affect the quality of the game. Physical regeneration and psychological assistance in setting other goals for the prospective elite level plays a vital role in material support. Training conditions - halls and sports facilities, traveling to different cities, many clubs and teams have unalike opportunities for training, many individuals have to travel too far which is time-consuming and tiring. Prospects of the country - engaging in the 
first league of men and women; going abroad; salary conditions; support for basketball by the state. Staff members - masseurs, doctors, sports psychologists who do not appear in the youth basketball in Slovakia.

The potential for the future relates to the environment. It is a vision of a certain status if youth stays on a basketball track, often due to their positive experience. Many players search for an opportunity abroad. Unfortunately, many see it as a risk in comparing their abilities with players from other, more evolved countries, so they choose to end their career early. Nevertheless, they want to keep doing sport, mainly basketball recreationally, or to get another sports-related profession - coach, referee, or physiotherapist. "I cannot be happier about the care our youth sport gets. However, I know it might be a problem if I won't get any offer from abroad when it comes to the transition from juniors to the men's league. I know that on the professional level it's not the best, but I do believe it'll be okay. Fingers crossed for me and other guys, for everyone."

\section{Atmosphere - team spirit}

Emphasis is placed on cooperation between teammates "... that we can hold each other up. We are friends even outside of the court; we trust each other everywhere." and moreover, coaches. "Coach cannot always be, like, shouting at us. We wouldn't enjoy playing in an atmosphere like that; we would stop. The atmosphere at the training and in the team, it has to work."

The dual relationship is vital in establishing a relationship as coach-trainee, person to person. Equivalence and justice - every player should be treated equally. Even the weaker ones should be a proper part of the team, they should see and feel their value. "One for all, all for one. Charisma. To have respect from the players. That's the most important because if players start to make fun of their coach, it's the worst."

Players should trust their coach to lead them adequately, to take care of them, give them the opportunity to play, "to show off." They need to have the confidence that coach will take care of them, will trust them and help them. "Trust in one another, that's the most important aspect." "It's good when the training sessions are freer, there's not too much tension. Then we go there full of joy; we work a lot harder because we love it. Of course, the coach should be strict but not in a way we would be scared of him."

The basketball and its cohesiveness guarantee a common emotional experience. Players enjoy their participation fully or suffer together when they lose. This experience adds to the value of basketball and sport itself. "If something goes wrong, guys don't blame anyone. They start to shout, start to chant for us, that's the best when we root for each other."

"It's the most beautiful sport existing."

"Those who were able to build themselves in it, stay in it."

\section{Are there gender differences relating to the determinants of the motivation?}

Regarding the genders, their answers were very similar. One of the reasons for terminating their basketball career is education and necessity to get an offer from abroad which results in subjective feelings of inadequacy. Nevertheless, it is clear that this age group already decided for or against continuing with professional sports career. The decision is influenced by the complex process of determinants starting in their childhood and is ongoing to their present day. 


\section{DISCUSSION}

Motivation and adherence are elements linked to passion interconnected with the professional sport. The results and their application to existing theories point to the importance of a sufficient educational environment in the sporting process. This process is formed and should be formed by the coach with the help of specialists such as sports psychologist.

Described determinants show the meaning of terms self-realization and sense of life. They represent enrichment for the age of adolescence. They can help the so-called anchoring of youth to a specific action that leads to a healthy lifestyle if applying the right approach. At the same time, they represent a potential for the future career in something they enjoy. Youth has a unique space where they may mentally unwind, find the group they belong to; they can figure out their own identity. Young basketball players see this sport as a purposeful activity with a meaning. Self-realization in basketball offers a room for enrichment, even creativity which connects with Maslow's (2000) theory of pyramid of needs. Before a person can fully develop their potential, they must meet the basic needs. Material support from parents assists with physiological needs and the need for security and safety. Emotional support fulfils the need for love and compassion. Informational support assists them to meet the needs of reaching firm competencies. Athletes aged 15-18 will develop their individual needs even after entering the professional sport. They will have to secure themselves, find new friends, set up their own families, and gain other specific competencies.

Motivation to play basketball professionally connects with experiencing the passion. This sport is regarded as meaningful and gives youth a sense of life - they demonstrate their capabilities to their selves and others. Basketball lets them find "asylum," the safe space where they can reach their potential goals if they attain the elite level. In the case of involuntary career termination or loss of enthusiasm, they may experience an existential crisis when they do not know where to go next (Frankl, 1999). For this age period, any crisis is intense. Youth encounters many crises and obstacles (changes in the body, transitioning from high school to college, choosing and planning for another potential occupation).

An overview of the options in self-realization provides a specific model of the motivational structure (Macák \& Hošek, 1989). It monitors the level of one's sporting performance and the level of competition. The first stage is biological motivation: the determinants associated with the need to move or with hyperactivity, feeling good about physical health. In the second stage stands a material motivation: athletes see the rewards of their work, they are interested in the specific sport, they form a relationship with it even when losing, they can achieve self-realization which leads them to choose the basketball as a profession. Pedagogical motivation: the coach plays a vital role at the younger age (teaching the technique or life values in later life). Young basketball players learn through the challenges that sport conveys, their performance improves, and they try to achieve their goals. Psychological motivation involves demonstration of personality, abilities, characteristics, will, resilience presented at the junior level. Young basketball players notice everything basketball has taught them and developed in them (endurance, purposefulness, independence). They have enough willpower to move further despite possible obstacles. Basketball as a team sport puts a strong emphasis on social motivation. They seek good relationships with teammates and coaches, even with opponents. Sport influences their socialization. Political motivation is the last stage where sportsperson grows into a versatile individual if there are right conditions present.

Basketball players get a chance to introduce themselves to new people, cultures which can provide a healthy development of their opinions and values, their worldview grows. If they internalize them, they may transfer them into their future life and profession. Travelling and exposure to many new things is not only an enriching aspect but also a stress factor which should be adequately addressed (Cosh \& Tully, 2015). 
The approach of coaches and teachers means a significant result. Their cooperation may reduce organizational demands on players (not reducing the demands of education and sports training). It could help with the sufficient time management allowing the athlete to succeed in both areas and work on their dual career (Stambulova \& Wylleman, 2014). Focusing on the mastery goals is an essential element confirmed by the feedback from the coaches. As long as the youth enjoys the practice and the matches, basketball keeps being the source of joy which results in young players to wish to stay in sports and to give an ample performance.

Coach needs to possess enough skills for creating cohesion within the team, to know how to approach their players as one unit and as individuals. They should be able to balance emotions and rationality, to create an exciting training plan, to actively listen, and be careful in the early specialization of their players. If a coach starts with a sportsperson's specialization early and the young player is not ready (mentally or physically), it can discourage them. If they create an adequate environment, the youth will have the safe space to enjoy basketball and connection with the ball, to mentally relax from the difficulties of other areas of life. If they leave the professional sport, they will remain in recreational sport relishing it thoroughly. Faith in a young athlete gives them the opportunity to develop as a person and as a player, to perceive their competencies, which brings a desire to improve and achieve higher goals.

\section{CONCLUSIONS}

We identified eight main determinants of motivation at the stage of selective self-realization: lifestyle, own perception skills, basketball specifics, time management, and health from a biopsychosocial point of view, enjoyment, environment and team spirit (team atmosphere). These determinants entwine with the passion that brings and maintains the motivation of basketball player. The motivation and passion result in adherence to the basketball which points to the dedication for the chosen sport even under challenging conditions. Results show that sport can bring a certain meaning, sense of life to an individual; basketball helps to fulfil physical and mental needs. In conclusion, it is imperative to create and maintain orientation on task. Sport should be a source of fun which should be reflected in a professional sport also. Not everyone can win, it is essential to get a good feeling of achieving high performance, satisfaction with oneself. It is necessary to nourish the passion in the youth so they may adhere to the sport, either professionally or recreationally.

\section{Disclosure statement}

The authors report no conflicts of interest. The authors alone are responsible for the content and writing of this article.

\section{References}

Alfermann, D., \& Stambulova, N. (2007). Career Transitions and Career Termination. In G. Tenenbaum \& R.C. Eklund (Eds.), Handbook of sport psychology (3rd ed., pp.712-736). New York, NY: Wiley.

Almagro, B. J., Conde, C., Sáenz-López, P. \& Moreno, J. A. (2009). Analysis and comparison of adolescent athletes' motivation: basketball players vs. football players. Revista de Psicología del Deporte, 18, 353-356

Ames, C. (1992). Achievement goals and the classroom motivational climate. In D. H. Schunk \& J. L. Meece (Eds.), Student perceptions in the classroom (pp. 327-348). Hillsdale, NJ, US: Lawrence Erlbaum Associates, Inc.

Bedrnová, E., \& Nový, I. (1998). Psychologie a sociologie řizení. Praha: Management Press

Bělohlávek, F. (2001). Management. Olomouc: Rubico

Bloom, B. S. (1985). Developing Talent in Young People. New York, NY: Ballantine Books. 
Corbin, J. M., \& Strauss, A. (1990). Grounded theory research: Procedures, canons, and evaluative criteria. Qualitative Sociology 13(1), 3-21. https://doi.org/10.1007/BF00988593

Cosh, S. \& Tully, P. J. (2015). Stressors, Coping, and Support Mechanisms for Student Athletes Combining Elite Sport and Tertiary Education: Implications for Practice. The Sport Psychologist, 2015, 29, 120-133. http://dx.doi.org/10.1123/ tsp.2014-0102

Cote, J. (1999). The Influence of the Family in the Development of Talent in Sport. The Sport Psychologist, 13(4), $395-417$.

Cox, R. H. (1994). Sport psychology concepts and application. Dubuque, I. A: Brown \& Benchmark.

Czikszentmihalyi, M., \& Larson, R. W. (1984). Being adolescent. New York, NY: Basic Books.

Dawes, N. P., Vest, A., \& Simpkins, S. (2013). Youth Participation in Organized and Informal Sports Activities across Childhood and Adolescence: Exploring the Relationships of Motivational Beliefs, Developmental Stage and Gender. Journal of Youth and Adolescence, 43, 1374-1388. http://dx.doi.org/10.1007/s10964-013-9980-y

Duda, J. L., \& Hall, H. K. (2001). Achievement Goal Theory in Sport: Recent Extensions and Future Directions. In R. Singer, C. Janelle, \& H. Hausenblas (Eds). Handbook of Research in Sport Psychology, 2nd ed. (pp. 417-443). New York, NY: John Wiley \& Sons Inc.

Duda, J. L., \& Nicholls, J. G. (1992). Dimensions of achievement motivation in schoolwork and sport. Journal of Educational Psychology, 84(3), 290-299.

Duda, J. L., \& Treasure, D. C. (2010). Motivational Processes and the Facilitation of Quality Engagement in Sport. In J. M. Williams (Ed.), Applied Sport Psychology: Personal Growth to Peak Performance (pp. 59-80). New York, NY: McGraw-Hill.

Dworkin, J. B., Larson, R., \& Hansen, D. (2003). Adolescents' Accounts of Growth Experiences in Youth Activities. Journal of Youth and Adolescence, 32, 17-26.

Frankl, V. (1999). Teorie a terapie neuróz. Praha: Grada Publishing.

Gillet, Nicolas \& Vallerand, Robert \& Rosnet, Elisabeth. (2009). Motivational clusters and performance in a real-life setting. Motivation and Emotion. 33. 49-62. 10.1007/s11031-008-9115-z.

Gould, D., Dieffenbach, K., \& Moffett, A. (2002). Psychological talent and their development in Olympic champions. Journal of Applied Sport Psychology, 14, 172-204. doi:10.1080/10413200290103482

Gómez-López, M., Gallegos, A. G., Abraldes, A. J., \& Suárez, N. R. (2013). Analysis of Self-determined Motivation in Basketball Players through Goal Orientations. Collegium Antropologicum, 37(3). 707-715.

Gregor, T. (2013). Psychológia športu. Bratislava: MAURO Slovakia.

Hendl, J. (2016). Kvalitativní výzkum: Základní teorie, metody a aplikace. Praha: Portál.

Hollings, S. C., Mallett, C. J., \& Hume, P. A. (2014). The Transition from Elite Junior Track-and-Field Athlete to Successful Senior Athlete: Why Some Do, Why Others Don't. International Journal of Sports Science \& Coaching, 9(3), 457-471.

Jarvis, M. (2006). Sport Psychology. A Student's Handbook. New York: Routledge.

Larson, R. W., \& Verma, S. (1999). How Children and Adolescents Spend Time Across the World: Work, Play and Developmental Opportunities. Psychological Bulletin, 125, 701-736.

Lochbaum, M. R., \& Roberts, G. C. (1993). Goal Orientations and Perceptions of the Sport Experience. Journal of Sport and Exercise Psychology, 15, 160-171.

Macák, l., \& Hošek, V. (1989). Psychologie tělesné výchovy a sportu. Praha. Štátne pedagogické nakladatel'stvo.

Munroe-Chandler, K. J. (2005). A discussion on qualitative research in physical activity. Athletic Insight 7(1). Retrieved May 23, 2005, from http://www.athleticinsight.com /Vol7lss1/QualitativeResearch.htm

Nicholls, J. G. (1984). Achievement motivation: Conceptions of ability, subjective experience, task choice, and performance. Psychological Review, 91, 328-346.

Petitpas, A. J., Champagne, D., Chartrand, J., Danish, S., \& Murphy, S. (1997). Athlete's Guide to Career Planning. Keys to Success from the Playing Field to Professional Life. Champaign, IL: Human Kinetics.

Pummell, B. Harwood, Ch., \& Lavallee, D. (2008). Jumping to the Next Level: A Qualitative Examination of Within-Career Transition in Adolescent Event Riders. Psychology of Sport and Exercise, 9, 427-447. http://dx.doi.org/10.1016/j.psychsport.2007.07.004

Ryan, R. M., \& Deci, E. L. (2002). An Overview of Self-determination Theory: An Organismic-Dialectical Perspective. In E. L. Deci \& R. M. Ryan (Eds.), Handbook of Self-determination Research (pp. 3-33). Rochester, NY: University of Rochester Press.

Salmela, J. H. (1994). Phases and Transitions across Sports Career. In D. Hackford (Ed). Psycho-social Issues and Interventions in Elite Sport (11-28). Frankfurt Germany: Lang.

Scanlan, A., Humphries, B., Tucker, PS., \& Dalbo, V. (2014). The Influence Of Physical And Cognitive Factors On Reactive Agility Performance In Men Basketball Players. Journal of Sports Sciences, 32(4), 367-374. http://dx.doi.org/10.1080/ 02640414.2013.825730

Slepička, P., Hošek, V., \& Hátlová, B. (2009). Psychologie sportu (2nd ed.). Praha: Karolinum.

Stelter, Reinhard; Sparkes, Andrew \& Hunger, Ina (2003). Qualitative Research in Sport Sciences—An Introduction [11 paragraphs]. Forum Qualitative Sozialforschung / Forum: Qualitative Social Research, 4(1), Art. 2, http://nbn-resolving. de/urn:nbn:de:0114-fqs030124.

Svobodová Z. a kol. (4/2017 - 12/2017). Životní príběh sportovce po vrcholové kariéře. [ROZV/25/FSpS/04/2017]

Trninić, S. (2000). Recognizing, Evaluating and Encouraging the Elite Basketball Players. Zagreb: Croatian Basketball Federation. Vallerand, R. J, \& Losier, G. F. (1999). An Integrative Analysis of Instrintic and Extrintic Motivation in Sport. Journal of Sport and Exercise Psychology, 11, 142-169. 
Vallerand, R. J., Mageau, G. A., Ratelle, C., Leónard, M., Vlanchard, C., ... Marsolais, J. (2003). Les Passions de L'a me: On Obsessive and Harmonious Passion. Journal of Personality and Social Psychology, 85(5), 756-767. http://dx.doi. org/10.1037/0022-3514.85.4.756

Vallerand, R. J., Mageau, G. A., Elliot, A. J., Dumais, A., Demers, M., \& Rousseasu, F. (2008). Passion and Performance Attainment in Sport. Psychology of Sport and Exercise, 9, 373-392. https://doi.org/10.1016/j.psychsport.2007.05.003

Vaněk, M., Hošek, V. \& Man, F. (1982). Formování výkonové motivace. Praha: Univerzita Karlova.

Votík, J. (2011). Fenomény vývoje sportovní kariéry v generačním kontextu Československých fotbalových reprezentantů. Praha: Grada Publishing.

Wylleman, P., \& Lavallee, D. (2004). A Developmental Perspective on Transitions Faced By Athletes. In M. Weiss (Ed.), Developmental sport and exercise psychology: A lifespan perspective (pp. 507-527). Morgantown, WV: Fitness Information Technology.

Stambulova, N., \& Wylleman, P. (2014). Athletes' career development and transitions. In A. Papaioannou, \& D. Hackfort (Eds.), Routledge companion to sport and exercise psychology (pp. 605-621). Routledge, London/New York. 